- Molar apicectomy with amalgam root-end filling attracted an overall 5-year 'complete healing' rate of 57\%.

- The results were best with mandibular first molars and worst with mandibular second molars. The prognosis was

also better if there was 'good' orthograde root filling in situ at the outset, an associated radicular cyst rather than apical granulomatous change and where the buccal sulcus was deep rather than shallow. It was worse when orthograde root filling was absent and when there was disease at the furcation.

- The apical ends of the roots were commoner sites of failure than the furcation. Purely lateral failure was not seen.

- The significant complication was impaired sensation in the lower lip following mandibular molar apicectomy. This occurred for a variable period in $20-21 \%$ of cases. A permanent deficit followed in $1 \%$. There was a threefold increase in the frequency of the latter after second molar apicectomy compared with first molar apicectomy.

- 'Complete healing' at 1 year was maintained in $75 \%$ of cases at 5 years.

\title{
Molar apicectomy with amalgam root-end filling: results of a prospective study in two district general hospitals
}

\author{
C. M. Wesson ${ }^{1}$ and T. M. Gale ${ }^{2}$
}

\begin{abstract}
Aim To determine the five-year success rates, site or sites of failure, prognostic indicators and lower lip morbidity associated with molar apicectomy using amalgam root-end filling.

Design Multicentre, prospective study.

Setting The departments of oral and maxillo-facial surgery in two district general hospitals.

Method One thousand and seven molar apicectomy procedures, combined with amalgam root-end filling were expedited during the period 1974-1995. A five-year review of each operated tooth was carried out or attempted between 1979-2000.

Results Of the 790 (78\%) operated molars successfully reviewed at 5 years or later 451 (57\%) exhibited 'complete healing' and 39 (5\%) 'uncertain healing.' Three hundred (38\%) were classified as 'unsatisfactory healing' (failures), and these included 12 which were assumed to be of periodontal origin. Whilst longitudinal root fracture, perforation and/or infection in the furcation, periodontal disease or a non-restorable crown accounted for treatment failure and often the need to remove teeth subsequently, the study probably pointed to the apical ends of the roots rather than the furcation as being the major sites at which 'unsatisfactory healing' occurred. Mandibular first molars attracted the highest 'complete healing' rate (60\%) and mandibular second molars the lowest (46\%).

'Good' root canal treatment (RCT) at the outset improved the prognosis of a root-end filling (REF) whilst the absence of RCT compromised it. Cystic change pointed to a better prognosis than apical granulomatous change as did a deep compared with a shallow 'bone cuff'. Disease at the furcation suggested a worse prognosis. Teeth which showed 'complete healing' at 1 year had a 75\% probability of maintaining this outcome at 5 years. Sensory disturbance of variable duration occurred in the lower lip following 20-21\% of mandibular molar procedures. In the majority of cases (79-80\%) this had remitted within 3 months. A permanent deficit occurred in 8 patients (1\%) where the apicectomy could definitely be incriminated as causative. Four were associated with first molar apicectomy and four with second molar apicectomy.
\end{abstract}

1*Formerly Consultant, Oral and Maxillo-Facial Surgeon, Queen Elizabeth II Hospital, Welwyn Garden City and The Luton and Dunstable Hospital; ${ }^{2}$ Statistician, University of Hertfordshire and Queen Elizabeth II Hospital, Welwyn Garden City

*Correspondence to: Colin Wesson, Wellspring, Old Rydon Lane, Exeter, EX2 7JZ Email: t.gale@herts.ac.uk

\section{Refereed Paper}

doi:10.1038/sj.bdj.4810834

Received 24.09.01; Accepted 30.06.03

๑ British Dental Journal 2003; 195: 707-714
Conclusions Molar apicectomy with amalgam root-end filling attracts an overall 'complete healing' rate at 5 years of $57 \%$, the results being best with mandibular first molars and worst with mandibular second molars. The prognosis is also better where there is 'good' initial orthograde root filling, an associated radicular cyst as compared with granulomatous change and where the buccal sulcus is deep rather than shallow. It is worse when orthograde root filling is absent and when there is disease in the furcation. 'Complete healing' at 1 year can be expected to be maintained at 5 years in $75 \%$ of cases. The commonest site of subsequent periradicular rarefaction seems to be 'apical' whilst failure at the furcation is probably comparatively rare. There is a threefold increase in the occurrence of permanent lower lip sensory impairment following second molar surgery in comparison with first molar surgery, the overall incidence being $1 \%$.

In recent years there have been important innovations in the practice of endodontic surgery. In particular, the early part of the last decade saw the introduction of the surgical microscope to the speciality (providing, for example, sharper visibility of apices and isthmuses). ${ }^{1}$ At the same time the development of ultrasonic tips for root-end preparation combined with miniaturized instruments allowed, inter alia, easier access, improved cavity preparation prior to root end filling (REF) and reduced bevelling. ${ }^{2}$ Meanwhile, the emergence of some new REF materials, including dentine-bonding composite ${ }^{3,4}$ and notably, mineral trioxide aggregate, ${ }^{5}$ has seemed also to hold out the prospect of an advance. Whilst the data reported in this paper concerning the comparative success rates of apicectomy with amalgam REF associated with the different molars, the probable sites of failure and the risks of damage to the inferior dental nerve (IDN) in mandibular molar apicectomy continue to have relevance, our overall outcomes seem to belong to a technique which has now been largely superseded, although longterm, large-scale evidence for this is as yet mostly lacking. Nevertheless, it is to be observed that gaining access for the surgical microscope to the mandibular second molar is extremely difficult if not impossible ${ }^{6}$ and a similar problem can be experienced with the palatal roots of maxillary molars. ${ }^{7}$

Previous reports of the outcome of apicectomy with amalgam REF on molars have been scarce and usually restricted to a low number of cases. ${ }^{8-10}$ However, there have been numerous large studies of the efficacy of the procedure on anterior and premolar teeth, yielding an average success rate of only 50-70\% with results widely spread on either side of these figures. ${ }^{11-13}$ One molar study by Rud 
et al. using amalgam did review many more cases than previous investigators. This confirmed a level of success within this range, finding a 'complete healing' rate of $61-62 \%$ in 203 cases at 1 year. ${ }^{3}$

It may be true that, because of the excellent results usually to be anticipated from modern RCT, ${ }^{13}$ resort to the surgical option is now less required in the management of periapical inflammation/ infection than formerly, although it continues to have a role especially when the apical end of an infected root canal is not accessible to orthograde instrumentation. Nevertheless, failure can occur in any tooth which appears well root-treated on a radiograph ${ }^{14}$ and orthograde re-treatment does not attract the same level of success as initial RCT. ${ }^{15}$ Traditionally, in connection with molar teeth specifically, the perception has tended to be that the outcome of RCT here is likely to be worse than for other teeth. In fact some studies have confirmed this ${ }^{16-19}$ but others have not. ${ }^{20-23}$ What is evident, however, is that molar RCT has become more widely practised in recent years and, in consequence, the number of molars being orthograde root-filled has now actually outstripped the number of anterior teeth so treated (Table 1). ${ }^{24}$ The backup option of molar apicectomy may therefore need to be increasingly considered in the future.

Table 1 Number of anterior v molar RCTs carried out in the General Dental Services of England and Wales from 1985-2003

\begin{tabular}{llllll}
\hline Date & Total RCTs & Anteriors & $\%$ & Molars & $\%$ \\
\hline 1985 & $1,192,930$ & 412,750 & 35 & 373,270 & 31 \\
\hline $1991 / 92$ & $1,270,268$ & 423,058 & 33 & 425,410 & 34 \\
\hline $1995 / 96$ & $1,195,899$ & 352,087 & 29 & 437,940 & 37 \\
\hline $1999 / 00$ & $1,181,179$ & 321,277 & 27 & 440,013 & 37 \\
\hline $2000 / 01$ & $1,129,683$ & 311,252 & 28 & 428,574 & 38 \\
\hline $2001 / 02$ & $1,114,755$ & 300,892 & 27 & 424,035 & 38 \\
\hline $2002 / 03$ & $1,085,749$ & 288,996 & 27 & 418,009 & 38 \\
\hline
\end{tabular}

Data supplied by the Dental Practice Board

\section{MATERIALS AND METHODS}

In 1974, in an attempt to access specifically the molar apicectomy with amalgam root-end filling more thoroughly with regard to its efficacy, sites of failure, prognostic indicators and morbidity, a prospective study was set up in the departments of oral and maxillo-facial surgery at two district general hospitals: the Queen Elizabeth II Hospital, Welwyn Garden City and the Luton and Dunstable Hospital. A form for the recording of information was prepared and duplicated setting out as many parameters as possible and pre-operative, intra-operative and post-operative data were noted when and after this treatment was instituted. Pre-operative assessment and treatment planning were carried out by the first author only and involved a determination of symptomatology, physical signs, the absence or presence and degree of periodontal disease, type of coronal restoration and radiographic details. The latter covered the presence or absence of RCT and, if present, an evaluation of its quality (root fillings short of the apices by more than $2 \mathrm{~mm}$ were regarded as incomplete ${ }^{21}$ but we found satisfactory obturation of furcal canals more difficult to assess). In addition, the radiographs were examined for, in particular, the presence of rarefaction periapically, laterally or at the furcation. Surgery was carried out mainly by the first author or at least under his supervision. Intra-operative findings which were noted included the presence or absence of periradicular disease - its site and (provisional) nature (confirmed subsequently by histology) and a naked-eye estimation of the distance in $\mathrm{mm}$ of the surgical cavity from the alveolar crest prior to closure (the remaining buccal/ palatal cortical bone being termed 'the bone cuff') (Figs.1,2). In the case of upper molars, an average figure was arrived at for buccal and palatal aspects. If the 'bone cuff' was deficient at any point then this value was entered as zero. Post-operatively, the initial objective was to review patients at 1 week, 1 year and 5 years and to obtain a periapical radiograph at these stages, noting any symptomatology and physical signs as well as radiographic data. In the case of lower molars, if a sensory deficit was reported in the lower lip post-operatively patients were monitored (almost always by the first author).

By 1995 1,007 procedures had been carried out and all operated teeth had been included in the study. One-week review presented few problems but many patients did not respond to a routine 1year recall. In cases where longer-term follow-up proved still more difficult (as it very frequently did) a determined effort was made by the first author between 1979-2000 to contact each patient by telephone and invite them at the 5-year post-operative stage or later for assessment (general dental practitioners and/or general medical practitioners and the Family Health Services Authority were often essential in locating patients). If it proved impossible for patients to return for review, GDPs were approached and their co-operation solicited in connection with the collection of the necessary data and the securing of a periapical radiograph. The latter was then inspected subsequently by the first author.

Molar apicectomy is very suitable for day-case surgery and almost invariably nasal endotracheal anaesthesia, which makes access more straightforward, was used. Only three mandibular first molars and one maxillary first molar were operated upon using local analgesia.

In this study all molar roots were apicected and only 16 were not root-end filled because they appeared to be well-obturated at operation. Twelve were palatal and four were mandibular second molar roots. The procedure involved the use of burs and a slowspeed, straight handpiece with water cooling. Magnification was not employed. Although the hope was always to preserve as much tooth substance as possible a steep angle of resection $\left(40^{\circ}\right.$ to the long axis of the root on average) was often necessitated to allow access for root-end cavity preparation and filling especially with second molars (Figs. 1,2). This could result in a minimal 'bone cuff' $(1 \mathrm{~mm})$ over mandibular second molars in particular, or might sometimes mean no 'cuff' at all in the case of palatal roots (the lat-

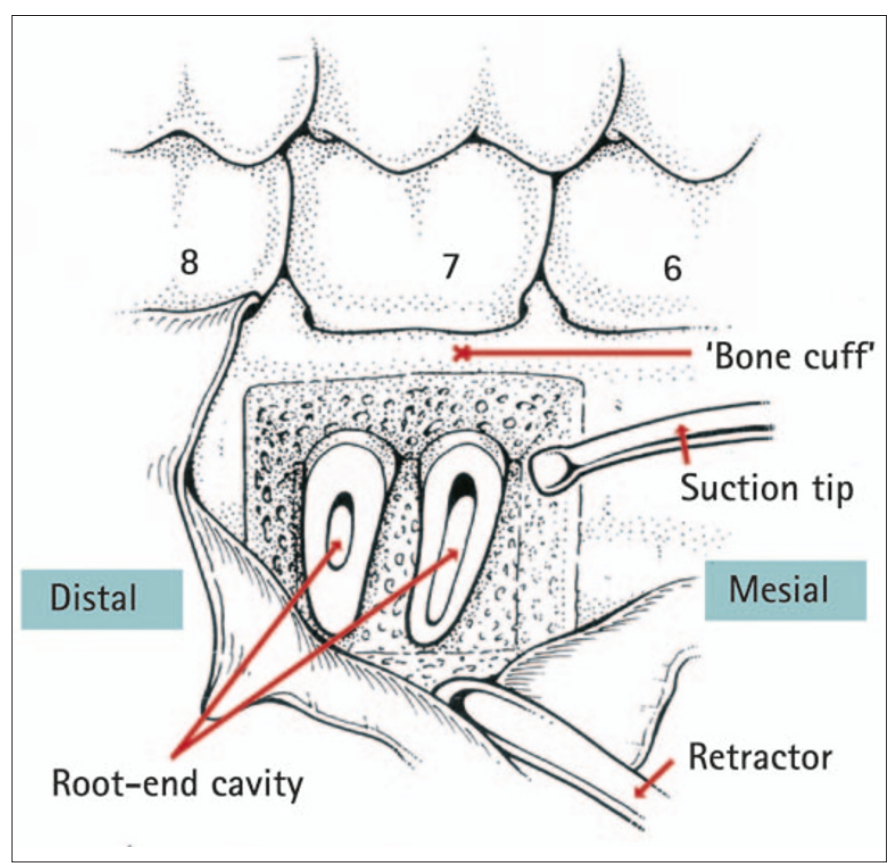

Fig. 1 Illustration of the approach to the root-end filling of a lower molar. Note the obliquity of root section and the retention of the teeth in occlusion - both to facilitate access 


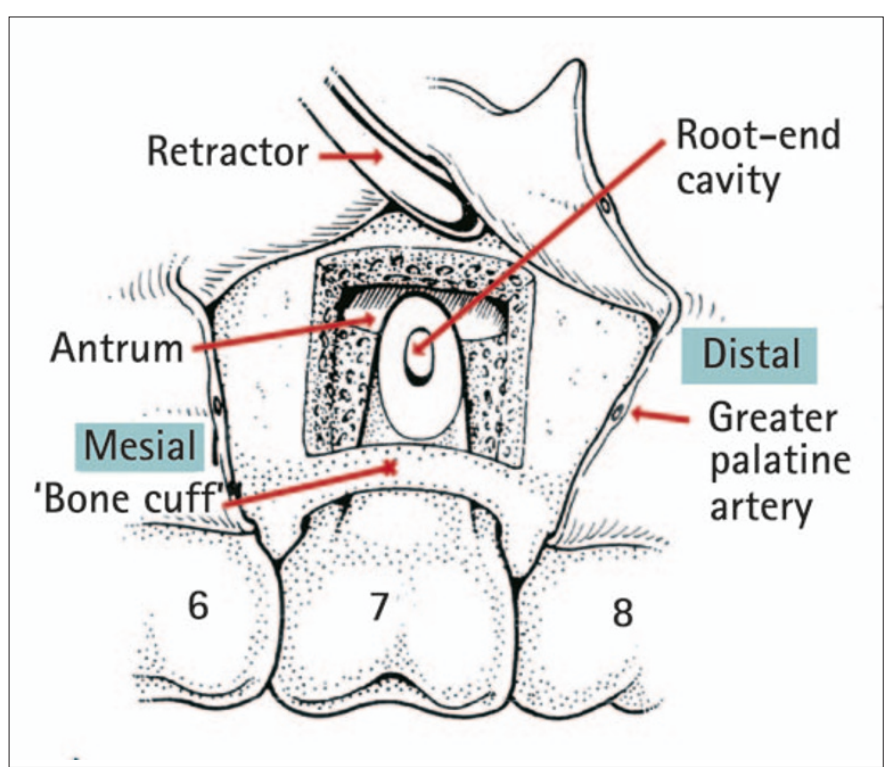

Fig. 2 Illustration of the palatal approach to the root-end filling of the palatal root of an upper molar. Note that the mouth is opened as wide as possible to facilitate access

ter were almost always approached palatally). Zinc-free high copper, silver amalgam (Vivadent), mechanically mixed, was used as the root-end filling material. Orthopantomographs (OPGs) and Kodak C58 Ultraspeed periapical radiographs (using a freehand, bisecting angle technique) were regarded as mandatory with the exception that pre-operatively an OPG alone was sometimes viewed as acceptable for lower molars - not least as providing an indication of the relationship between the IDN and the mandibular molar apices. An illuminated radiographic viewing box equipped with a separate spotlight facility corresponding to the size of a periapical film, and excluding extraneous light, was used to assess intraoral radiographs. Evaluation was carried out by a single observer (the first author).

In those cases where the mandibular second molar was deemed to be too close to the IDN (ie where they appeared to be in contact on the OPG or within $0.5 \mathrm{~mm}$ of that situation) apicectomy was not recommended. Likewise, treatment was not carried out if a tooth appeared to be longitudinally fractured or if there was evidence of a perforation in the furcation. In practice, this latter complication was only very rarely concluded to have supervened if rarefaction changes were absent at this site. On the other hand, when there was a radiolucency in the furcation only with no evidence of an inflamed or non-vital pulp we assumed, even when there was no periodontal probing defect, that the problem was periodontal rather than endodontic in origin and therefore again excluded such patients from the study. However, in those cases where there was evidence of rarefaction both at the periapex and furcation - often in obvious continuity - apicectomy was not necessarily considered inappropriate because of the possibility that apical disease had extended coronally and thus the furcation had perhaps become secondarily involved. ${ }^{25}$ Teeth with advanced periodontal disease (more than $3 \mathrm{~mm}$ pocket depth) and the medically compromised patient were, as a rule, not regarded as candidates for this procedure. A 5-day course of antibiotics (usually Amoxil) was routinely prescribed post-operatively and started 1-hour pre-operatively. Chlorhexidine mouthwash and analgesics were also provided following surgery and sutures were removed at 1 week.

The data from all proformas were coded and collated on a Power Macintosh ${ }^{\mathrm{TM}}$ microcomputer using the Statview package. All planned tests and associations between pre-, inter-, and postoperative variables and outcome status were computed using
Chi-square tests except where stated. Values of Chi-square corresponding to a probability level of $<0.05$ were considered to be statistically significant.

\section{RESULTS}

Outcomes at 5 years or later were classified into five cohorts and these are presented in Tables 2 and 3 (Rud et al.'s criteria for assessing radiographic healing following apical surgery were used $^{26}$ ). The reasons for loss of patients to full 5-year follow-up are analysed in Table 4.

\section{Data collected post-operatively at or after 5 years}

The following parameters were recorded at the outset and the extent to which these were associated with success or failure then quantified at 5 years (or later):

\section{Age}

Five hundred and three cases were in the under 45 age group and 251 were in the 45 years or over group (in 36 cases the data on age were lost). In the under 45 group 298 (59\%) emerged as 'completely healed', $23(5 \%)$ as 'uncertain' and $182(36 \%)$ as 'unsatisfactory' whilst in the 45 years or over group 147 (59\%) showed 'complete healing', 14 (6\%) were 'uncertain' and 90 (36\%) ‘unsatisfactory'.

\section{Sex}

There was a preponderance of females, 502 (64\%) compared with 288 (36\%) males. Two hundred and ninety four females (59\%) emerged as 'completely healed', 20 (4\%) as 'uncertain' and 188 $(37 \%)$ as 'unsatisfactory' whilst 160 males (56\%) showed 'complete healing', 19 (7\%) were 'uncertain' and 109 (38\%) ‘unsatisfactory’.

\section{Type of molar}

The results in relation to the different molars are displayed in Table 5.

\section{The presence of good orthograde $R C T$}

Only 264 of our sample had initially received 'good' RCT and we operated upon 502 with either poor or no RCT, this being a reflection of our lack of a specialist endodontist (in 12 cases data on RCT were missing). Of those with 'good' RCT 161 (61\%) showed 'complete healing' whilst in $95(36 \%)$ periradicular healing was judged to be 'unsatisfactory' and in 8 (3\%) 'uncertain' (Table 6).

Table 2 5-year healing cohorts following molar apicectomy with amalgam root-end filling $(n=790)$ (cf. Rud et al. ${ }^{26}$ )

1. Complete periradicular healing $451(57 \%)$ Here there were no symptoms, no physical signs and complete radiographic healing.

2. Uncertain periradicular healing $39(5 \%)$ Here there were no clinical features but the radiograph revealed periapical rarefaction of up to $1 \mathrm{~mm}$ width involving one or more roots.

3. Unsatisfactory periradicular healing (failure) See Table 3.

4. Combined periradicular and periodontal failure Here failure was assumed to be due mainly to periodontal breakdown but unsatisfactory periradicular healing was also present:

(i) Tooth removed

(ii) Tooth retained periradicular healing' with retention of the tooth. 
Table 3 Unsatisfactory periradicular healing (failure) $(n=288)$ (periodontal failures excluded $(n=12)$ )

Presumed sites and/or nature of failure during the 5-year post-operative period:

a) In association with tooth removal $(n=174)$ or exploration prior to re-apicectomy $(n=18)$

1. Poor apical seal only (with or without macroscopic 'apical' infection)

2. Poor apical seal and macroscopic furcation infection

3. Macroscopic furcation infection only

4. Non-restorable crown

5. Root fracture

6. Obvious perforation in the furcation

7. Unknown

b) In association with tooth retention and no interceptive oral surgical treatment $(n=88)$

1. No periradicular radiographic rarefaction (but with clinical features)

2. Radiographic rarefaction at the furcation only (with $(n=4)$ or without clinical features $(n=4)$

3. Radiographic rarefaction at the furcation and 'apical' sites (with $(n=3)$ or without clinical features $(n=4)$

4. Radiographic 'apical' rarefaction only (with $n=27$ ) or without clinical features $(n=34)$ and exceeding $1 \mathrm{~mm}$ width.

c) In association with tooth retention and interceptive RCT $(n=8)$

1. Poor apical seal only

2. Radiographic rarefaction at the furcation only within 5 years of the apicectomy whilst 18 had undergone re-apicectomy and 8 interceptive RCT. Re-apicectomy attracted 'complete healing' in only 4 cases (22\%) whilst, in contrast, interceptive RCT was followed by this outcome in 6 (75\%).

\section{Lower lip morbidity}

Between 1974 and 1999 a total of 770 mandibular molars underwent apicectomy with root-end filling (601 first, 164 second, 5 third). These included not only those teeth in the main 1974-1995 study $(n=530)$, but also those within this period which had been lost to full 5-year follow-up, where nevertheless data on lower lip morbidity had been obtained earlier $(n=130)$, together with those patients operated between 1995-1999 and therefore not

\begin{tabular}{|c|c|c|c|c|}
\hline Tooth & $n$ & $\begin{array}{l}\text { 'Complete } \\
\text { healing' }\end{array}$ & $\begin{array}{l}\text { 'Uncertain } \\
\text { healing' }\end{array}$ & $\begin{array}{l}\text { 'Unsatisfactory } \\
\text { healing' }\end{array}$ \\
\hline Mandibular first molar & 419 & $252(60 \%)$ & $19(5 \%)$ & $148(35 \%)$ \\
\hline Mandibular second molar & 106 & 49 (46\%) & $6(6 \%)$ & $51(48 \%)$ \\
\hline Mandibular third molar & 3 & $1(33 \%)$ & $0(0 \%)$ & $2(67 \%)$ \\
\hline Maxillary first molar & 225 & $130(58 \%)$ & $13(6 \%)$ & $82(36 \%)$ \\
\hline Maxillary second molar & 36 & $19(53 \%)$ & $1(3 \%)$ & $16(44 \%)$ \\
\hline Maxillary third molar & 1 & $0 \quad(0 \%)$ & $0(0 \%)$ & $1(100 \%)$ \\
\hline Totals & 790 & 451 (57\%) & $39(5 \%)$ & $300(38 \%)$ \\
\hline
\end{tabular}

Table 4 Classification of reasons for loss to full follow-up of molars at 5 years $(n=217)$

\begin{tabular}{|c|c|}
\hline \multicolumn{2}{|l|}{ 1. Tooth extracted by GDP: a) before 5 years } \\
\hline b) after 5 years (ie follow-up delayed) & $57(26 \%)$ \\
\hline 2. Emigration of patient & $15(7 \%)$ \\
\hline 3. Death of patient & $4 \quad(2 \%)$ \\
\hline 4. Patient too debilitated to attend & $(1 \%)$ \\
\hline 5. Refusal of review appointment & $25(12 \%)$ \\
\hline 6. Refusal to allow radiography & $4 \quad(2 \%)$ \\
\hline 7. Patient untraceable & $55(25 \%)$ \\
\hline 8. Residential data lost & $31(14 \%)$ \\
\hline 9. Inadequate records & $(7 \%)$ \\
\hline
\end{tabular}

\section{The absence of orthograde RCT}

Absence of RCT was confirmed throughout the study period in the case of 20 teeth. All of these showed periradicular rarefaction. In $17(85 \%)$ this was exclusively periapical and in $3(15 \%)$ both at the furcation and periapex (Table 10).

The presence or absence of radiological changes

The data here are set out in Table 7. A radicular 'cyst' was histologically confirmed and was understood as a pathological cavity having fluid or semi-fluid contents which was not created by the accumulation of pus but which was frequently lined by epithelium. ${ }^{27}$

\section{Depth of buccal/palatal 'bone cuff'}

The intra-operative findings vis-à-vis the depth of the buccal/ palatal 'bone cuff' prior to closure (Figs. 1,2) are shown in relation to the 5-year healing cohorts in Table 8.

\section{One-year versus five-year data}

It proved possible to review only 339 (43\%) of the 790 molars at 1 year and the data for these comparing the 1-year with the 5-year healing cohorts are presented in Table 9.

\section{Unsatisfactory healing (failures)}

Three groups could be identified here and these are analysed in Table 3. One hundred and seventy four molars were removed
Table 6 Number and percentages of teeth with 'good' initial orthograde root fillings in the different 5-year healing cohorts

\begin{tabular}{lr}
\hline 5 -year cohort & 'Good' root filling $(n=264)$ \\
\hline 'Complete healing' & $161(61 \%)$ \\
\hline 'Uncertain healing' & $8(3 \%)$ \\
\hline 'Unsatisfactory healing' & $95(36 \%)$ \\
\hline
\end{tabular}

Table 7 The influence of the presence or absence of preoperative radiographic rarefaction on healing at 5 years following molar apicectomy $(n=778)$ (Periodontal failures excluded $(n=12)$

\begin{tabular}{|c|c|c|c|c|}
\hline \multirow{2}{*}{$\begin{array}{l}\text { Pre-operative } \\
\text { groups } \\
\text { Classification of initial } \\
\text { involvement by radiographic } \\
\text { rarefaction: its presence or } \\
\text { absence, distribution and } \\
\text { nature }\end{array}$} & \multirow[b]{2}{*}{$n$} & \multicolumn{3}{|c|}{$\begin{array}{l}\text { Healing outcome at } 5 \text { years } \\
\text { expressed as percentage of numbers initially } \\
\text { involved in each group } \\
\text { (actual numbers in brackets) }\end{array}$} \\
\hline & & $\begin{array}{l}\text { 'Complete } \\
\text { healing' }\end{array}$ & $\begin{array}{l}\text { 'Uncertain } \\
\text { healing' }\end{array}$ & $\begin{array}{l}\text { 'Unsatisfactory } \\
\text { healing' }\end{array}$ \\
\hline $\begin{array}{l}\text { A. Apical, non-cystic } \\
\text { rarefaction only }\end{array}$ & 454 & $57 \%(261)$ & $7 \%(30)$ & 36\% (163) \\
\hline $\begin{array}{l}\text { B. Apical, non-cystic } \\
\text { rarefaction with rarefaction } \\
\text { at the furcation }\end{array}$ & 50 & $40 \%(20)$ & $6 \%(3)$ & $54 \%(27)$ \\
\hline $\begin{array}{l}\text { C. No periradicular } \\
\text { rarefaction }\end{array}$ & 242 & $62 \%(149)$ & $2 \%(5)$ & $36 \%(88)$ \\
\hline D. Cystic rarefacton & 28 & $71 \%(20)$ & $4 \%(1)$ & $25 \%(7)$ \\
\hline $\begin{array}{l}\text { E. Non-cystic rarefaction } \\
\text { at the furcation only }\end{array}$ & 1 & $100 \%(1)$ & 0 & 0 \\
\hline Inadequate data & 3 & & & 3 \\
\hline Totals & 778 & 451 & 39 & 288 \\
\hline
\end{tabular}

Table 8 Resulting 5-year cohorts in relation to the intra-operative vertical depth of the 'bone cuff(s)' $(n=790)$ (see Figs.1,2)

\begin{tabular}{lrcrc}
\hline $\begin{array}{l}\text { Depth of } \\
\text { cuff (in } \mathrm{mm})\end{array}$ & Totals & $\begin{array}{c}\text { 'Complete } \\
\text { healing' }\end{array}$ & $\begin{array}{c}\text { 'Uncertain } \\
\text { healing' }\end{array}$ & $\begin{array}{c}\text { 'Unsatisfactory } \\
\text { healing' }\end{array}$ \\
\hline 0 & 89 & $41(46 \%)$ & $5(6 \%)$ & $43(48 \%)$ \\
\hline 1 & 95 & $45(47 \%)$ & $5(5 \%)$ & $45(47 \%)$ \\
\hline 2 & 374 & $207(55 \%)$ & $15(4 \%)$ & $152(41 \%)$ \\
\hline Not recorded & 67 & 32 & $3(2 \%)$ & $36(22 \%)$ \\
\hline
\end{tabular}




\begin{tabular}{|c|c|c|c|c|}
\hline \multirow{2}{*}{\multicolumn{2}{|c|}{ Healing cohorts at 1 year }} & \multicolumn{3}{|c|}{$\begin{array}{l}\text { Healing cohorts at } 5 \text { years } \\
\text { Subsequent } 3 \text { healing cohorts emerging } \\
\text { at } 5 \text { years from each } 1 \text {-year cohort }\end{array}$} \\
\hline & & 'Complete' & 'Uncertain' & 'Unsatisfactory \\
\hline 'Complete' & 198 (58\%) & $148(75 \%)$ & $10 \quad(5 \%)$ & $40 \quad(20 \%)$ \\
\hline 'Uncertain' & 79 (23\%) & $49 \quad(62 \%)$ & $8(62 \%)$ & $22(28 \%)$ \\
\hline 'Unsatisfactory' & $62(18 \%)$ & 17 (27\%) & $1 \quad(2 \%)$ & $44 \quad(71 \%)$ \\
\hline
\end{tabular}

Table 10 Sites of 'unsatisfactory healing' at 5 years in cases without RCT $(n=20)$

$$
\begin{aligned}
& \text { i. Periapical rarefaction only: } 17 \\
& \text { ii. Rarefaction at the furcation and 'periapex': } 3 \\
& \text { iii. Rarefaction at the furcation only: } 0
\end{aligned}
$$

recalled for 5-year follow-up $(n=110)$ although they had been seen post-operatively in the interim. There were 32 teeth with missing data and therefore 738 mandibular molars available for evaluation (582 first, 152 second and 4 third).

No third molar procedures were associated with a post-operative sensory deficit and analysis of the remaining 734 first and second molars revealed that there was a range of $151(20 \%)$ to 157 (21\%) within which sensory disturbance occurred. This was because 12 of the apicected teeth associated with this complication belonged to 6 patients where adjacent first and second molars had been operated upon together and here only one procedure may have compromised the IDN (Fig. 3). Moreover, this range of totals could involve an overestimate because in 18 concomitant other procedures had been carried out and these could have compromised the IDN instead (removal of impacted wisdom teeth, impacted premolars or retained roots and premolar apicectomies).

The duration of lower lip sensory disturbance following either first or second molar apicectomy is presented in Fig. 4 where two categories have been omitted:

1. The above six pairs of adjacent molars where separation into tooth type in terms of resulting nerve morbidity was impossible (in three of these a deficit was present for up to 1 week, in one up to 1 month and in two up to 3 months).

2. Procedures which were known to have resulted in lower lip morbidity post-operatively but where its duration was unknown because the patients were subsequently lost to follow-up. There were 13 in this group. Two involved second molars (last seen at 1 week and 1 year respectively) and 11 were carried out on first molars (eight being last seen at 1 week, one at 3 months and two at 1 year).

Because the actual numbers shown in Fig. 4 do not include the above two categories the percentages expressed are in relation to 565 first and 144 second molar procedures. Depending on whether one or both teeth in the six pairs were associated with compromise of the IDN, there was a minimum of $120(79 \%)$ or a maximum of $126(80 \%)$ cases where the lower lip sensory deficit was found to have remitted within 3 months. In ten (1\%) it was known to have persisted for more than 2 years and therefore was regarded as permanent. Analysis of these disclosed that four patients experienced paraesthesia/hypersensitivity with normal or increased response to pin prick whilst in two patients there was complete loss of response to pin prick. Two patients reported numbness of the lower lip more than 2 years following surgery but declined to return. The two remaining patients had complete loss of sensation to pin prick subsequent to 2 years but both these had simultaneously undergone the removal of deeply impacted teeth (one wisdom and one second premolar) and it must remain doubtful whether the apicectomy procedure was responsible for the deficit.
Of the eight patients with permanent sensory disturbance where the apicectomy could definitely be regarded as causative, four (1\%) underwent first molar apicectomy and four (3\%) second molar apicectomy.

\section{DISCUSSION}

\section{Radiographic evaluation}

It is acknowledged that the radiographic results reported in this paper must be viewed with caution. In particular, given the quest for evidence-based dentistry and the emphasis on the need in research for multiple examiners of endodontic radiographs, ${ }^{28,29}$ the follow-up radiographic data recorded here (depending as they do on only one periapical radiograph and upon observation by only one examiner (the first author) without measuring intra-observer variation), are not as accurate as they could have been. These shortcomings need to be borne in mind when interpreting the results.

\section{Site(s) of failure}

Whilst root fracture $(n=21)$, a non-restorable crown $(n=11)$ and periodontal disease $(n=12)$ could account for early removal in a minority of cases, it emerged that either the 'apical' ends of the roots or the furcation were the most likely pathways for the leakage of toxins and/or microbes in molar apicectomy $(n=256)$ (Table 3). Purely lateral failure was not observed.

Estimates for the frequency of communications between the pulp chamber and the periodontium vary widely in the literature. Some workers have reported a high incidence $e^{30-34}$ whilst others, in contrast, have been unable to confirm this. ${ }^{35-39}$ Nevertheless, it is plainly important for this possible site of failure to be properly sealed at the time of RCT. ${ }^{39,40}$ In our study, GDPs were encouraged to arrange for RCT post-operatively where it had not been expedited beforehand and in fact we identified only 20 teeth where this had been absent throughout the study period (Table 10). Whilst all of these showed periradicular rarefaction (reinforcing the importance of RCT) none revealed rarefaction at the furcation only - although we recognise that detection of disease at the trifurcation in its earlier stages is problematic if not impossible. Thus our data suggest that the primary location for failure in molar apicectomy is probably 'apical' - such that numbers in the sub-categories (ii) and (iii) of Table 10 were too small to permit statistical analysis.

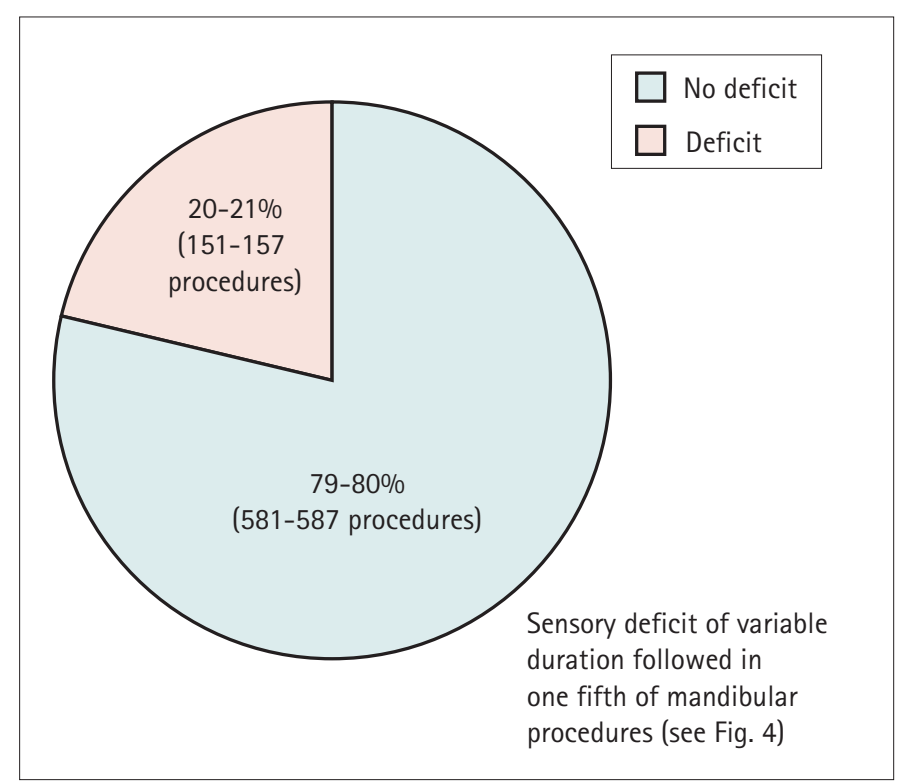

Fig. 3 Pie chart showing overall incidence of lower lip sensory deficit analysis of 738 mandibular molar procedures 
$\%$ Mandibular molar procedures

with sensory deficit

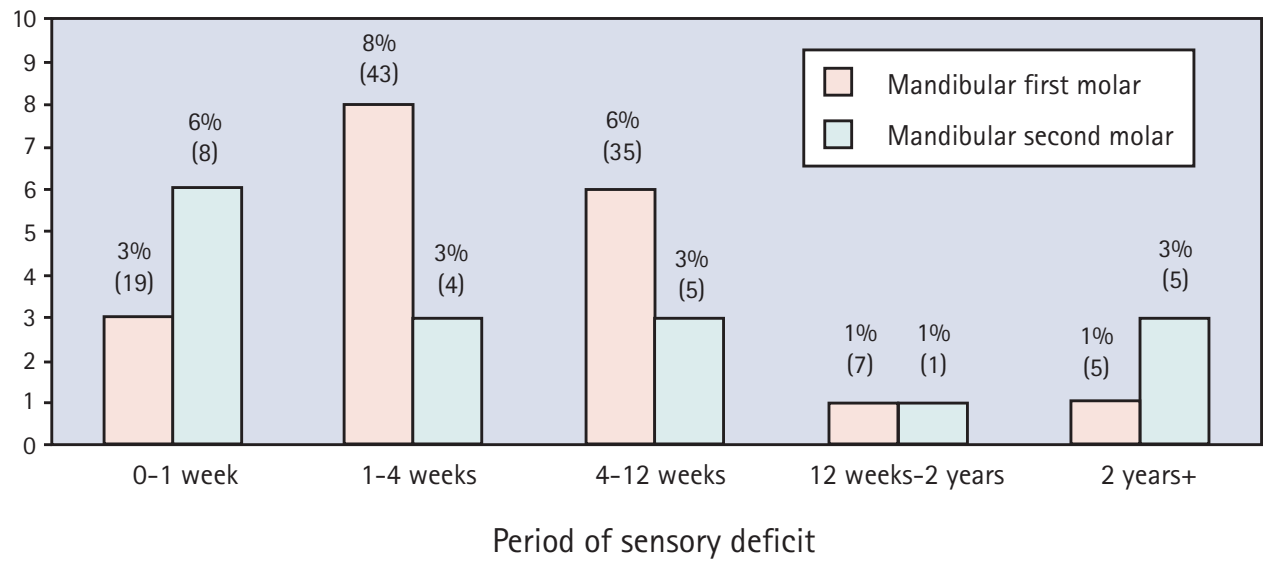

The $y$ axis displays mandibular molar apicectomies associated with a sensory deficit at different post-operative time intervals expressed as a percentage of 565 first and 144 second molar procedures

Fig. 4 Duration of lower lip sensory deficit (actual numbers in brackets)

Current laboratory studies have highlighted two 'apical' routes which toxins/microbes might take to reach the periodontium from an infected canal: on the one hand, sectioned dentinal tubules are a probable avenue. ${ }^{41,42}$ Furthermore their contribution to lack of healing will almost certainly have been increased by the steep bevel we often found necessary to achieve adequate access - resulting inevitably in a sharp rise in their number (Figs. 1,2)..$^{43}$ On the other hand, and leaving aside the controversy over the disadvantages of amalgam in terms of its toxicity, ${ }^{44-47}$ it has been shown that this filling material is probably subject to significant leakage, especially initially. ${ }^{12,48-50}$ In our study the situation will have been compounded by the frequent difficulty we experienced in securing a bloodless field despite our use of high-speed suction. This too was related to poor access which could also create problems in allowing satisfactory amalgam condensation.

\section{Should all molar roots be included in the surgical procedure?}

In our project the view was taken that all molar roots should be apicected and root-end filled. In some molar apicectomy studies, clinicians have avoided surgery on one or more roots (eg the palatal root of upper molars). ${ }^{8,10,51}$ It may have been that effective RCT/re-RCT of such roots was seen as a more practicable option instead, or that an existing orthograde root filling was associated with an uncompromised periapex and seemed to be providing satisfactory obturation suggesting that surgical intervention was unnecessary. However, it needs to be recalled that an orthograde root filling which appears well-executed on a standard periapical film may have gross shortcomings revealed if radiographs are taken in a mesio-distal direction on teeth subsequently extracted. ${ }^{52}$ Likewise, at the histological level, it has been noted in teeth which have been removed later that the satisfactory pre-extraction radiographic appearance of an orthograde root filling cannot guarantee that a root canal has been adequately obturated. ${ }^{53}$ Therefore when molars are undergoing apical surgery, if the complete orthograde filling and obturation of any of the root canals, as advocated, for example, by Pitt Ford et al. in connection with single-rooted teeth, ${ }^{54}$ cannot be assured, then that root should be included in the surgical procedure even when there is no periradicular rarefaction on the radiograph.

\section{COMPLICATIONS}

Historically, apicectomy on molar teeth has tended to be avoided because of the risk of damage to the IDN (in the case of mandibular molars) or of antral complications (in the case of maxillary molars) as well as doubts as to its efficacy and problems with access. Two previous studies of mandibular molar apicectomy have recorded the incidence of lower lip morbidity. In one, 39 procedures resulted in three instances $(8 \%)$ of a sensory deficit - lasting at most 6 months, although the identity of the tooth associated with this complication was not made clear. ${ }^{10}$ In the other, 726 procedures resulted in post-operative paraesthesiae in 26 patients (4\%) with this complication being reported after 1 year in only one patient, although again the tooth involved was not indicated. ${ }^{4}$ In our study, whilst no mandibular first molars were omitted on the grounds of proximity to the IDN, very rarely mandibular second molars could be excluded for this reason. Nevertheless our data pointed to the conclusion that the proportion followed by a permanent sensory deficit was significantly higher for mandibular second molars (3\%) than for first molars (1\%) (Fisher's exact test $P<0.05)$. The actual risk ratio for mandibular second molars was 3.8 (95\% Confidence Interval 1.2 to $12.1: P=0.02$ ) (Fig. 4).

With regard to antral problems following maxillary molar surgery, the intention to record this complication was abandoned early because of difficulties in measurement and because of its seeming extreme rarity.

\section{PROGNOSTIC CONSIDERATIONS}

Rud et al. showed in their study of (predominantly) anterior teeth that a successful outcome at 1 year tended to be maintained with only very mild diminution subsequently. ${ }^{11}$ Our results were not so impressive. We found that the prognosis for teeth associated with 'complete healing' at 1 year was only a $75 \%$ probability of continuing in the same cohort at 5 years whilst the outcome for those with 'unsatisfactory healing' at 1 year meant a similar probability of 71\% remaining in this failure category (Table 9).

However, a major objective of the project was to identify any indicators which could point at the outset to either a good or bad prognosis. We assumed that longitudinal root fracture, perforation in the furcation, rarefaction in the furcation in isolation (and not of periodontal origin) or gross periodontal disease were suggestive of a hopeless outcome and any teeth so involved were excluded. We then evaluated the following factors: 


\section{Age}

Age was not a significant predictor of outcome in our patients $\left(\chi^{2}[\mathrm{dfl}]=0.05, P=0.82\right)$. Some studies of anterior apicectomy have reported similarly ${ }^{55,56}$ although Harty et al. found that those under 45 did significantly better. ${ }^{57}$

\section{Sex}

Sex likewise was not a significant predictor of outcome $\left(\chi^{2}[\mathrm{dfl}]\right.$ $=0.561, P=0.45$ ).

\section{Molar type}

There was a significant correlation between 'complete healing' and molar type $(P<0.05)$ (Table 5). Post-hoc cell contributions were greatest for mandibular first and second molars and suggested that mandibular first molars attract the best 'complete healing' rate $(60 \%)$ whilst mandibular second molars have the worst "unsatisfactory' healing rate. The latter had a 'complete healing' rate of 46\%. The results for maxillary first and second molars fell between these.

\section{The presence or absence of orthograde RCT}

There was a correlation between the presence of 'good' RCT and success (Table 6). This is in line with those animal and human studies which have suggested that good preliminary orthograde root filling of single-rooted teeth improves the prognosis of a REF. Such studies have inferred furthermore that lack of good RCT compromises (or is likely to compromise) the outcome. ${ }^{54,58,59}$ We were able to confirm this latter conclusion in the case of 20 teeth where RCT was absent throughout the study period and where in all instances periradicular rarefaction supervened, involving the periapex alone in the majority (Table 10).

\section{The presence or absence of periradicular rarefaction}

We found that the prognosis for teeth with initial periapical, noncystic rarefaction and that for teeth with no rarefaction did not differ significantly (Table 7) (in particular, both groups registered 36\% 'unsatisfactory healing'). Our results here therefore did not agree with those authors who have noted that single-rooted teeth with initial periapical rarefaction attract a poorer prognosis following apical surgery than those with no rarefaction at all or only widening of the lamina dura (ie those which would now be placed in the 'uncertain' cohort). ${ }^{56,57,60-62}$ However, our data did point to a worsening of the prognosis when the furcation was involved at the outset, although this did not reach a level of statistical significance (Table 7).

Whilst we acknowledge that we did not routinely measure the precise size of all periapical areas, we did, on the basis of naked-eye observation, record the presence of a presumed 'cyst' - ie where an associated radiolucency was judged to have a diameter of $1 \mathrm{~cm}$ or more, ${ }^{63}$ but this was always checked histologically. Surprisingly, although our results did not reach a level of statistical significance, we found that cystic disease attracted a better prognosis than apical, non-cystic rarefaction (71\% 'complete healing' compared with 57\%) (Table 7). The explanation for this was not clear although others have recorded similarly in connection with (mainly) single-rooted teeth. ${ }^{64-67}$ Nevertheless some authors report that area size (and therefore cystic change) has no effect on prognosis ${ }^{56,62,68}$ whilst, in contrast, others have concluded that there is a better outcome when there is granulomatous as compared with cystic involvement. ${ }^{60,61}$ In fact our diagnostic and surgical method vis-à-vis presumed radicular 'cysts' has now been overtaken by the work of Nair et al. ${ }^{69-72}$ who have demonstrated on the basis of much more stringent clinical and histological evidence, and following Simon ${ }^{73}$ that there needs to be a drastic reduction in their perceived number in comparison with the much higher figures often published to date $\left(42-55 \%{ }^{74-76}\right)$. They calculate that the true incidence of self-sustaining radicular cysts among periapical lesions is only 9\% (interestingly, in our study they constituted an even smaller minority (4\%)).

\section{Depth of sulcus}

As the depth of the 'bone cuff' at closure increased the proportion of successes increased whilst that of failures decreased. This was highly significant $\left(\chi^{2}\right.$ test for trend $\left.[\mathrm{dfl}]=25.9, P<0.0001\right)$ (Table 8). Thus it is probably not unreasonable to expect that, in the absence of marginal bone loss, the proportion of those 'completely healed' will increase as the depth of the buccal sulcus (assumed to be a reflection of the height of the buccal bone covering the root) increases. ${ }^{77}$

Deficiencies in the seal afforded by a coronal restoration were not amongst the parameters recorded in this study. It was assumed that if shortcomings were present they would be rectified by the practitioner, if not before, then after surgery. There can now be little doubt that the quality of the fit of a coronal restoration will affect the prognosis of endodontically treated teeth. ${ }^{78,79}$

This work was partly supported by funding from the NHS Executive Eastern Region. The views expressed in this publication are those of the authors and not necessarily those of the NHS Executive Eastern Region.

The authors would like to thank Professor T. R. Pitt Ford for his valued critique of the manuscript together with his numerous suggestions for improvement. They would also like to express their appreciation to DrI. R. Harris for his helpful advice and to acknowledge the important assistance of those dental colleagues who provided follow-up data for some of the patients. Finally, they would like to record their gratitude to Joanne Spatz for the word-processing. In addition to the first author the surgery was carried out by Ms E. Rapaport, Drs. R. Chauhan, M. Kumar, S. Bass, A. G. Buchanan, T. Cudmore, M. Goodliffe, I. R. Harris, S. C. Jack, J. Munns, S. Pinto, T. Rajah and S. Rashid.

1. Kim S, Pecora G, Rubinstein R A. Colour atlas of microsurgery in endodontics. Philadelphia:W. B Saunders Co. 2001, pp. $95 f f$.

2. Carr G B. Ultrasonic root-end preparation. In Kim S. (Ed) 'Microscopes in Endodontics' Dent Clin N Amer 1997; 41: 541-554.

3. Rud J, Munksgaard E C, Andreasen J O, Rud V. Retrograde root filling with composite and a dentine-bonding agent. Part II. Endod Dent Traumatol 1991; 7: 126-131.

4. Rud J, Rud V, Munksgaard E C. Periapical healing of mandibular molars after root-end sealing with dentine-bonded composite. Int Endod J 2001; 34: 285-292.

5. Torabinejad M, Pitt Ford T R, McKendry D J, Abedi H R, Miller D A, Kariyawasam S P. Histologic assessment of mineral trioxide aggregate as a root-end filling in monkeys. JEndod 1997; 23: 225-228.

6. Kim S, Pecora G, Rubinstein R A. Colour atlas of microsurgery in endodontics. Philadelphia: W B Saunders Co. 2001, pp.19,127.

7. Saunders W P. Personal communication, 2001

8. Altonen M, Mattila K. Follow-up study of apicectomised molars. Int J Oral Surg 1976; 5: $33-40$.

9. Persson G. Periapical surgery of molars. Int J Oral Surg 1982; 11: 96-100.

10. Ioannides C, Borstlap W A. Apicectomy on molars: a clinical and radiographic study. Int J Oral Surg 1983; 12: 73-79.

11. Rud J, Andreasen J 0, Möller Jensen J E. A follow-up study of 1,000 cases treated by endodontic surgery. Int J Oral Surg 1972; 1:215-228.

12. Andreasen J O, Pitt Ford T R. A radiographic study of the effect of various retrograde fillings on periapical healing after replantation. Endod Dent Traumatol 1994; 10: 276-281.

13. Friedman S. Treatment outcome and prognosis of endodontic therapy in Ørstavik. D, Pitt Ford T R. (Ed.) Essential Endodontology. Oxford: Blackwell Science, 1998, pp367-401.

14. Siqueira J F. Aetiology of root canal treatment failure: why well-treated teeth can fail. Int Endod J 2001; 24: 1-10.

15. Sjögren U. Success and failure in endodontics. Umeo Univ. Odontological Dissertation. 1996 (Abst.60); $13 f, 24$.

16. Swartz D B, Skidmore A E, Griffin J A. Twenty years of endodontic success and failure. JEndod 1983: 9: 198-202.

17. Smith C S, Setchell D J, Harty FJ. Factors influencing the success of conventional root canal therapy: a five-year retrospective study. Int Endod J 1993; 26: 321-333.

18. Friedman S, Löst C, Zarrabian N, Trope M. Evaluation of success and failure after endodontic therapy using a glass ionomer cement sealer. J Endod 1995; 21: 384-390.

19. Peak J D, Hayes S J, Bryant S T, Dummer P M H. The outcome of root canal treatment: A retrospective study within the Armed Forces (Royal Air Force). Br Dent J 2001; 190: 140-144.

20. Engström B, Hard A F, Segerstad L, Ramstrom G, Frostell G. Correlation of positive cultures with the prognosis for root canal treatment. Odontologisk Revy 1964; 15 257-270.

21. Strindberg $L Z$. The dependence of the results of pulp therapy on certain factors: an analytic study based on radiographic and clinical follow-up examinations. Acta Odont Scand 1956; 14: Suppl 21

22. Grahnen $H$, Hansson $L$. The prognosis of pulp and root canal therapy: a clinical and radiographic follow-up examination. Odontologisk Revy 1961; 12: 146-165.

23. Heling B, Tamshe A. Evaluation of the success of endodontically treated teeth. Oral Surg 1970; 30: 533-536.

24. Dummer PM H. The quality of root canal treatment in the general dental services. 
Dent Profile (J Dent Pract Board Eng Wales) 1997; 17: 5-6.

25. Simon J H S, Glick D H, Frank A L. The relationship of endodontic-periodontic lesions. JPeriodontol 1972; 43: 202-208.

26. Rud J, Andreasen J 0, Möller Jensen J E. Radiographic criteria for the assessment of healing after endodontic surgery. Int J Oral Surg 1972; 1: 195-214.

27. Kramer IR H. President's address: changing views on oral disease. Proc Roy Soc Med 1974; 67: 273

28. Reit $\mathrm{C}$. The influence of observer calibration on radiographic periapical diagnosis. Int Endod J 1987; 20: 75-81.

29. Molven 0 , Halse A, Grung B. Observer strategy and the radiographic classification of healing after endodontic surgery. Int J Oral Maxillofac Surg 1987; 16: 432-439.

30. Kramer I R H. The vascular architecture of the human dental pulp. Arch Oral Biol 1960; 2: $177-189$

31. Lowman JV, Burke R S, Pelleu G B. Patent accessory canals: incidence in the molar furcation region. Oral Surg 1973; 36: 580-584.

32. Gutmann J L. Prevalence, location and patency of accessory canals in the furcation region of molars. J Periodontol 1978; 49: 21-26.

33. Vertucci FJ, Anthony R L. A scanning electron microscopic investigation of accessory foramina in the furcation and pulp chamber floor of molar teeth. Oral Surg 1986; 62: 319-326.

34. Niemann R W, Dickinson G L, Jackson C R, Wearden S, Skidmore A E. Dye ingress in molars: furcation to chamber floor. J Endod 1993; 19: 293-296.

35. Pineda F, Kuttler Y. Mesio-distal and bucco-lingual roentgenographic investigation of 7,275 root canals. Oral Surg 1972; 33: 101-110.

36. De Deus $Q \mathrm{D}$. Frequency, location and direction of the lateral, secondary, and accessory canals. J Endod 1975; 1: 361-366.

37. Kirkham D B. The location and incidence of accessory pulpal canals in periodontal pockets. J Am DentAssoc 1975; 91: 353-356.

38. Hession R W. Endodontic morphology: A radiographic analysis. Oral Surg 1977; 44: 610-620.

39. Welch J D, Anderson R W, Pashley D H, Weller N, Kimbrough W F. An assessment of the ability of various materials to seal furcation canals in molar teeth. J Endod 1996; 22: 608-611.

40. Saunders W P, Saunders E M. Assessment of leakage in the restored pulp chamber of endodontically treated multi-rooted teeth. Int Endod J 1990; 23: 28-33.

41. Chong B S, Pitt Ford T R, Kariyawasam S P. Tissue response to potential root-end filling materials in infected root canals. Int Endod J 1997; 30: 102-114.

42. Peters $L B$, Wesselink $P R$, Buijs $J F, V a n$ Winkelhoff $A J$. Viable bacteria in root dentinal tubules of teeth with apical periodontitis. J Endod 2001; 27: 76-81.

43. Gilheany P A, Figdor D, Tyas M J. Apical dentine permeability and microleakage associated with root-end resection and retrograde filling. J Endod 1994; 20: 22-26.

44. Pitt Ford T R, Andreasen J O, Dorn S O, Kariyawasam S P. Effect of IRM root-end fillings on healing after replantation. J Endod 1994; 20: 381-385.

45. Skoner J R, Wallace J A, Fochtman F, Moore PA, Zullo T, Hoffman R D. Blood mercury levels with amalgam retroseals: a longitudinal study. J Endod 1996; 22: 140-141.

46. Chong B S, Pitt Ford T R, Karyawasam S P. Short-term response to potential root-end filling materials in infected root canals. Int Endod J 1997; 30: 240-249.

47. Berry T G, Summitt J B, Chung A K H, Osborne J W. Amalgam at the new millennium. J Am Dent Assoc 1998; 129: 1547-1556.

48. Ghafouri S N, Ball P C, Fitch R K. The in-depth sealing properties of amalgam and composite restorative materials. Br Dent J 1982; 153: 400-403.

49. Thirawat J. Edmunds $D H$. The sealing ability of materials used as retrograde root fillings in endodontic surgery. Int EndodJ 1989; 22: 295-298.

50. Chong B S, Pitt Ford T R, Watson T F, Wilson R F. Sealing ability of potential retrograde root filling materials. Endod Dent Traumato/ 1995; 11: 264-269.

51. Friedman S, Lustmann J, Shaharabany V. Treatment results of apical surgery in premolar and molar teeth. JEndod 1991; 17: 30-33.

52. Kersten $\mathrm{H}$ W, Wesselink P R, Van Velzen T. The diagnostic reliability of the buccal radiograph after root canal filling. Int Endod J 1987: 20: 20-24.

53. Rud J, Andreasen J O. A study of failures after endodontic surgery by radiographic, histologic and stereomicroscopic methods. Int J Oral Surg 1972; 1: 311-328.
54. Pitt Ford $T R$, Roberts $G J$ J. Tissue response to glass ionomer retrograde root fillings. Int Endod J 1990; 23: 233-238.

55. Rud J Andreasen $\rfloor$, Möller Jensen E. A multivariate analysis of the influence of various factors upon healing after endodontic surgery. Int J Oral Surg 1972; 1: 258-271.

56. Grung B, Molven O, Halse A. Periapical surgery in a Norwegian county hospital; follow-up findings in 477 teeth. J Endod 1990: 16: 411-417.

57. Harty F J, Parkins B J. Wengraf A M. The success rate of apicectomy. Br Dent J1970; 129: 407-413.

58. Rud J, Rud V, Munksgaard E C. Effect of root canal contents on healing of teeth with dentine-bonded resin composite retrograde seal. J Endod 1997; 23: 535-541.

59. Danin J, Linder L E, Lundqvist G, Ohlsson L, Ramsköld L O, Strömburg T. Outcome of periradicular surgery in cases with apical pathosis and untreated canals. Oral Surg Oral Med Oral Path 1999; 87: 227-232.

60. Nordenram A, Svärdström G. Results of apicectomy. Swed Dent J 1970; 63: 593-604

61. Hirsch J M, Ahlstrom U, Henrikson P, Heyden G, Peterson L. Periapical surgery. Int J Oral Surg 1979; 8: 173-185.

62. Lustmann J, Friedman S, Shaharabany V. Relation of pre- and intra-operative factors to prognosis of posterior apical surgery. J Endod 1991; 17: 239-241.

63. McCall J O, Wald SS. Clinical Dental Roentgenology. 3rd ed. Philadelphia:W B Saunders Co. 1952, p.192

64. Mattila $\mathrm{K}_{1}$ Altonen M. A clinical and roentgenological study of apicoectomised teeth Odontol Tidskr 1968; 76: 389-407.

65. Ericson S, Finne K, Persson G. Results of apicectomy of maxillary canines, premolars and molars with special reference to oro-antral communication as a prognostic factor. Int J Oral Surg 1974; 3: 386-393.

66. Persson $G$, Lennartson $B$, Lundström I. Results of retrograde root filling with special reference to Amalgam and Cavit as root filling materials. Swed Dent J 1974; 67: 123 134.

67. Mikkonen M, Kullaa-Mikkonen A, Kotilainen R. Clinical and radiologic re-examination of apicoectomised teeth. Oral Surg Oral Med Oral Pathol 1983; 55: 302-306.

68. Rahbaran S. Gilthorpe N S, Harrison S D, Gulabivala K. Comparison of clinical outcome of periapical surgery in endodontic and oral surgery units of a teaching dental hospital: a retrospective study. Oral Surg Oral Med Oral Path 2001; 91: 700-709.

69. Nair P N R, Sjögren U, Schumacher E, Sundqvist G. Radicular cyst affecting a root-filled human tooth; a long-term post-treatment follow-up. Int EndodJ 1993; 26: 225-233.

70. Nair P N R, Pajarola G, Schroeder H E. Types and incidence of human periapical lesions obtained with extracted teeth. Oral Surg Oral Med Oral Pathol Oral Radiol Endod 1996; 81: 93-102.

71. Nair P N R. Review: new perspectives on radicular cysts: do they heal? Int Endod J 1998: 31: 155-160

72. Nair P N R, Sjögren U, Figdor D, Sundqvist G. Persistent periapical radiolucencies of root-filled human teeth, failed endodontic treatments and periapical scars. Oral Surg Oral Med Oral Pathol Oral Radiol Endod 1999; 87: 617-627.

73. Simon J H S. Incidence of periapical cysts in relation to the root canal. J Endod 1980; 6: $845-848$.

74. Priebe $W A$, Lazansky J $P$, Wuehrmann $A H$. The value of the roentgenographic film in the differential diagnosis of periapical lesions. Oral Surg Oral Med Oral Pathol 1954; 7: 979-983.

75. Bhaskar S N. Periapical lesions: types, incidence and clinical features. Oral Surg Oral Med Oral Pathol 1966; 21:657-671.

76. Lalonde E R. A new rationale for the management of periapical granulomas and cysts: an evaluation of histopathological and radiographic findings. J Am Dent Assoc 1970; 80:1056-1059.

77. Skoglund A, Persson G. A follow-up study of apicectomised teeth with total loss of the buccal bone plate. Oral Surg Oral Med Oral Pathol 1985; 59: 78-81.

78. Safavi KE, Dowden W E, Langeland K. Influence of delayed coronal permanent restoration on endodontic prognosis. Endod Dent Traumatol 1987; 3: 187-191.

79. Ray H A, Trope M. Periapical status of endodontically treated teeth in relation to the technical quality of the root filling and the coronal restoration. Int Endod J 1995; 28: $12-18$ 